\title{
Respiratory system compliance at the same PEEP level is similar in COVID and non-COVID ARDS
}

\author{
Federica Fusina ${ }^{1 *} \mathbb{B}$, Filippo Albani ${ }^{1}$, Serena Crisci ${ }^{1,2}$, Alessandro Morandi ${ }^{1}$, Francesca Tansini ${ }^{1,3}$, Rasula Beschi $^{1}$, \\ Antonio Rosano ${ }^{1}$ and Giuseppe Natalini ${ }^{1}$
}

\begin{abstract}
Background: The comparison of respiratory system compliance $\left(C_{r s}\right)$ between COVID and non-COVID ARDS patients has been the object of debate, but few studies have evaluated it when considering applied positive end expiratory pressure (PEEP), which is one of the known determinants of $C_{r s}$ itself. The aim of this study was to compare $C_{r s}$ taking into account the applied PEEP.
\end{abstract}

Methods: Two cohorts of patients were created: those with COVID-ARDS and those with non-COVID ARDS. In the whole sample the association between $C_{r s}$ and type of ARDS at different PEEP levels was adjusted for anthropometric and clinical variables. As secondary analyses, patients were matched for predicted functional residual capacity and the same association was assessed. Moreover, the association between $\mathrm{C}_{\mathrm{rs}}$ and type of ARDS was reassessed at predefined PEEP level of $0,5,10$, and $15 \mathrm{cmH}_{2} \mathrm{O}$ with a propensity score-weighted linear model.

Results: 367 patients were included in the study, 276 patients with COVID-ARDS and 91 with non-COVID ARDS. The association between $C_{r s}$ and type of ARDS was not significant in both the complete cohorts $(p=0.17)$ and in the matched cohorts $(p=0.92)$. This was true also for the propensity score weighted association at PEEP 5,10 and 15 $\mathrm{cmH}_{2} \mathrm{O}$, while it was statistically significant at PEEP $\mathrm{O}$ (with a median difference of $3 \mathrm{ml} / \mathrm{cmH}_{2} \mathrm{O}$, which in our opinion is not clinically significant).

Conclusions: The compliance of the respiratory system is similar between COVID ARDS and non-COVID ARDS when calculated at the same PEEP level and while taking into account patients' anthropometric characteristics.

Keywords: Respiratory system, Respiration, Artificial, Intensive care units, PEEP, Ventilation, Artificial, COVID-19, Respiratory system compliance

\section{Background}

Acute respiratory distress syndrome (ARDS) is common in severe novel coronavirus 2019 disease (COVID-19) [1]. Recently, it was suggested [2] that respiratory system compliance $\left(\mathrm{C}_{\mathrm{rs}}\right)$ might be different in COVID-ARDS when compared to ARDS from other diseases, due to the

\footnotetext{
*Correspondence: f.fusina@gmail.com

${ }^{1}$ Department of Anesthesia, Intensive Care and Pain Medicine, Fondazione Poliambulanza Hospital, via Bissolati, 57, 25124 Brescia, Italy

Full list of author information is available at the end of the article
}

existence of two different "phenotypes" in COVID ARDS which might not be present in non-COVID ARDS. These phenotypes have been identified as Type L, characterized by Low elastance (i.e., high compliance) and Type $\mathrm{H}$, characterized by High elastance (i.e., low compliance) [2]. Subsequent studies have compared $\mathrm{C}_{\mathrm{rs}}$ between COVID ARDS and non-COVID ARDS, but the debate concerning differences in $\mathrm{C}_{\mathrm{rs}}$ between COVID and non-COVID ARDS patients is still ongoing, due to conflicting findings [3-6]. original author(s) and the source, provide a link to the Creative Commons licence, and indicate if changes were made. The images or other third party material in this article are included in the article's Creative Commons licence, unless indicated otherwise in a credit line to the material. If material is not included in the article's Creative Commons licence and your intended use is not permitted by statutory regulation or exceeds the permitted use, you will need to obtain permission directly from the copyright holder. To view a copy of this licence, visit http://creativecommons.org/licenses/by/4.0/. The Creative Commons Public Domain Dedication waiver (http://creativeco mmons.org/publicdomain/zero/1.0/) applies to the data made available in this article, unless otherwise stated in a credit line to the data. 
$\mathrm{C}_{\mathrm{rs}}$ is modified by Positive End Expiratory Pressure (PEEP) levels [7-11], but previous studies have compared $\mathrm{C}_{\mathrm{rs}}$ between COVID ARDS and non-COVID ARDS at different PEEP levels [3, 5, 12]. Only by knowing $\mathrm{C}_{\mathrm{rs}}$ at similar PEEP levels can the $\mathrm{C}_{\mathrm{rs}}$ of COVID and non-COVID ARDS patients be correctly compared, thus avoiding attributing to respiratory system characteristics what could be the effect of PEEP itself on $\mathrm{C}_{\mathrm{rs}}$. Therefore, the aim of the study was to assess if $\mathrm{C}_{\mathrm{rs}}$ in COVID ARDS and non-COVID ARDS is similar or different when the applied PEEP is taken into account.

\section{Methods}

In this retrospective cohort study, data was collected from all consecutive adult subjects (over 18 years of age) with a diagnosis of ARDS (according to the Berlin Definition criteria [13]) to the Intensive Care Unit (ICU) of Poliambulanza Foundation Hospital of Brescia (Lombardy, Italy) from January 1st 2015 to May 1st 2021.The referral Ethics Committee (Comitato Etico di Brescia) approved the study (protocol number 4893).

Subjects were excluded from the analysis if: (a) they did not undergo invasive mechanical ventilation with sedation and paralysis; (b) no recordings of $\mathrm{C}_{\mathrm{rs}}$ at different PEEP levels during invasive ventilation with sedation and paralysis during the ARDS period were available.

Two cohorts of subjects were created: (1) subjects with COVID-19 ARDS, i.e., the ones with ARDS attributable to Severe Acute Respiratory Syndrome-CoronaVirus- 2 (SARS-CoV -2) infection. (2) subjects with non-COVID ARDS, i.e., ARDS subjects without SARS-CoV 2 infection. ARDS patients were included in this group if ICU admission occurred before February 18th 2020, the day of the first COVID-19 diagnosis in our region (RT-PCR test for SARS-CoV-2 was not performed before this date), or if they had a negative RT-PCR test for SARS-CoV-2 after 18th February 2021.

Data on respiratory mechanics were collected, on median, on the same day as ARDS diagnosis in both COVID ARDS and non-COVID ARDS $(0[0-1]$ and 0 $[0-1]$ days after ARDS diagnosis, respectively, $\mathrm{p}=0.51$ ). Tracheal intubation was performed, on median, on the same day as ARDS diagnosis in patients with COVID ARDS and on the day before ARDS diagnosis in patients with non-COVID ARDS $(0[0-1]$ and $1[0-1.5]$ days before ARDS diagnosis, respectively, $\mathrm{p}<0.001$ ).

All measurements were taken with patients in the semirecumbent position, sedated and paralyzed. Ventilatory settings were adjusted according to our ICU's ventilation protocol [4]: $\mathrm{C}_{\mathrm{rs}}$ at different PEEP levels was assessed with a "PEEP trial", setting volume controlled ventilation if not in use and maintaining the tidal volume set by the attending clinician in order to ensure a low-tidal volume ventilation. An end-inspiratory pause of $0.5 \mathrm{~s}$ was set and the respiratory rate was progressively decreased until complete exhalation was achieved. A stepwise increase (of $2 \mathrm{cmH}_{2} \mathrm{O}$ ) in PEEP level was performed, until an evident pattern of decrease of $\mathrm{C}_{\mathrm{rs}}$ with increasing PEEP was noticeable. The lowest PEEP level at which $\mathrm{C}_{\mathrm{rs}}$ was assessed in all patients was $4 \mathrm{cmH}_{2} \mathrm{O}$. A PEEP of 0 and $2 \mathrm{cmH}_{2} \mathrm{O}$ could be applied in patients with $\mathrm{SpO}_{2}$ higher than $85 \%$. Each PEEP level was maintained for at least 2 min [14]. When the PEEP trial was completed, the previous ventilatory mode and respiratory rate were restored, and PEEP was set to obtain a total PEEP equal to the PEEP associated with the highest $C_{r s}$ obtained during the PEEP trial. The PEEP trial was stopped when a systematic increase in driving pressure was seen with increasing PEEP, or when adverse cardiovascular effects or a decrease in $\mathrm{SpO}_{2}$ greater than $10 \%$ of baseline were noticed.

The "PEEP trial" was completed, on median, on the same day as intubation in all groups.

Data (demographic, clinical, laboratory data and outcome) were extracted from the electronic medical chart of enrolled subjects.

\section{Measurements and calculations}

Respiratory system compliance $\left(\mathrm{C}_{\mathrm{rs}}\right)$ was calculated as the ratio between tidal volume and driving pressure, which is the pressure distending the lungs, and is calculated as end inspiratory pressure (Plateau Pressure) minus PEEP [7].

"Best compliance" was identified as the highest $\mathrm{C}_{\mathrm{rs}}$ obtained at the tested PEEP levels and "best minimum PEEP" was the lowest PEEP with which the best compliance was obtained in each patient.

Body mass index (BMI) was calculated as $\mathrm{kg} / \mathrm{m}^{2}$, where $\mathrm{kg}$ is the weight in kilograms and $\mathrm{m}^{2}$ is the square of the height in meters.

Ideal Functional Residual Capacity (FRC) was calculated as 2.34.height in meters + 0.01.age in years -1.09 in male patients and as 2.24.height in meters +0.001 .age in years -1.00 in female patients [15]. Predicted FRC was obtained correcting for BMI with the following formula $231.9 \cdot \mathrm{e}^{(-0.070 \cdot \mathrm{BMI})}+55.2[16]$.

Ventilatory ratio was calculated as (tidal volume-respiratory rate $\left.\cdot \mathrm{PaCO}_{2}\right) /($ ideal body weight $100 \mathrm{ml} / \mathrm{min} \cdot 37.5 \mathrm{mmHg}$ ), where tidal volume is expressed in milliliters and 37.5 is assumed to be the $\mathrm{PaCO}_{2}$ during the ideal minute ventilation [17].

Ideal body weight (IBW) was calculated as $50+(0.91 \cdot$ [height in centimeters-152.4]) for men, and as $45.5+(0.91$. [height in centimeters -152.4$])$ for women. 


\section{Study outcomes}

The main study outcome was to assess if the $\mathrm{C}_{\mathrm{rs}}$ of the respiratory system was independently associated with the type of ARDS (COVID ARDS or non-COVID ARDS) when weighted for PEEP level and patients' baseline characteristics.

\section{Statistical analysis}

Sample size analysis was conducted with Montecarlo simulation based on data collected for a previous study [4]. Two hundred and sixty patients, hypothesising a ratio between COVID and non-COVID ARDS of 0.30, would guarantee a power of 0.80 to identify a difference in $C_{\mathrm{rs}}$ between the two groups of $5 \mathrm{ml} / \mathrm{cmH}_{2} \mathrm{O}$, with a type I error frequency of 0.05 .

Data are shown as count (percentage) or median (interquartile range) and comparison between non-COVID ARDS and COVID ARDS were performed with $x^{2}$ test and Wilcoxon rank-sum test, respectively.

We planned to analyze the association between $\mathrm{C}_{\mathrm{rs}}$ and type of ARDS at different PEEP levels, using linear mixed models. The dependent variable was $\mathrm{C}_{\mathrm{rs}}$ and the following covariates were chosen a priori: type of ARDS (COVID vs non-COVID), PEEP, age, sex, BMI, Ventilatory Ratio, tidal volume, $\mathrm{PaO}_{2} / \mathrm{FIO}_{2}$, with patients as random effect.

Two secondary analyses were planned, with the aim to repeat the analysis on matched samples: (1) two cohorts of non-COVID and COVID ARDS were created, matched for predicted FRC. Matching was performed with the nearest neighbor method. The association between $C_{\mathrm{rs}}$ and the type of ARDS (COVID versus non-COVID) was assessed with linear mixed models with interaction, using the type of ARDS and PEEP level at which $\mathrm{C}_{\mathrm{rs}}$ was measured as covariate, and patients as random effect. (2) The average respiratory system compliance $\left(\mathrm{C}_{\mathrm{rs}, \mathrm{avg}}\right)$ was calculated in each patient at a PEEP level of $0,5,10$, and 15 $\mathrm{cmH}_{2} \mathrm{O}$, taking the average $\mathrm{C}_{\mathrm{rs}}$ obtained at a PEEP of 0,5 , 10 and $15 \mathrm{cmH}_{2} \mathrm{O} \pm 2 \mathrm{cmH}_{2} \mathrm{O}$. The association between $\mathrm{C}_{\mathrm{rs}, \mathrm{avg}}$ and type of ARDS (COVID versus non-COVID) was reassessed at each of the four PEEP levels with linear model weighted with stabilized Inverse Probability Treatment Weighting obtained by propensity score [18]. Propensity score was calculated using age, sex, BMI, Ventilatory Ratio, tidal volume (used in the PEEP trial) and $\mathrm{PaO}_{2} / \mathrm{FIO}_{2}$ as covariates.

The analyses were repeated excluding non-COVID patients with extrapulmonary ARDS.

Missing values were imputed with Multivariate Imputation by Chained Equations (Predictive Mean Matching). A p value lower than 0.05 was considered significant. Statistical analyses were performed with R 3.6.3 (R Core Team, 2021. R Foundation for Statistical Computing, Vienna) [19].

\section{Results}

Three hundred sixty seven subjects were included in the study, 276 with COVID-ARDS and 91 with non-COVID ARDS (Fig. 1). Patient characteristics are shown in Table 1 . In 24\% of non-COVID ARDS patients, the cause of ARDS was extrapulmonary. Mean arterial pressure,

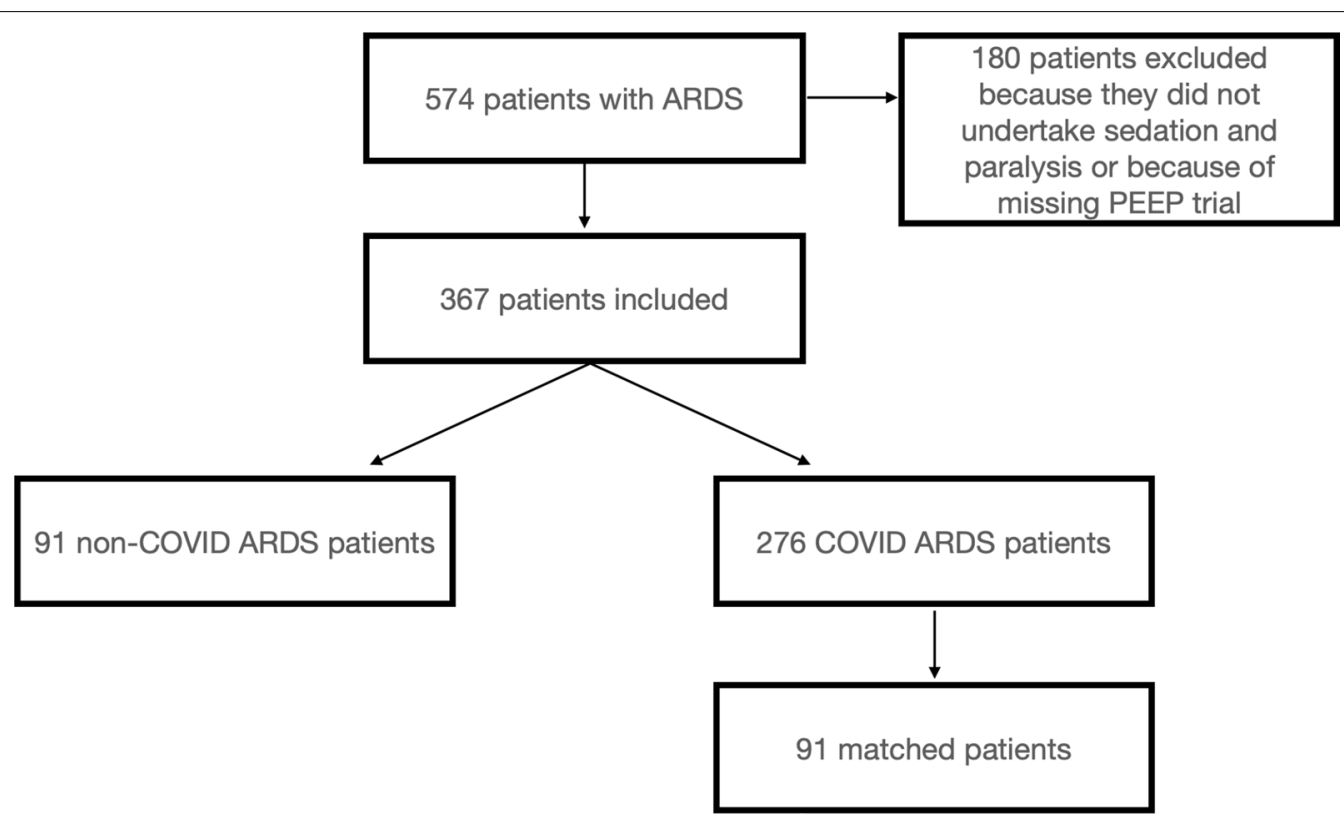

Fig. 1 Flowchart of patients included in the study. PEEP positive end expiratory pressure, ARDS acute respiratory distress syndrome 
Table 1 Patient characteristics

\begin{tabular}{|c|c|c|c|c|c|}
\hline & Non-COVID ARDS & COVID ARDS & p value & $\begin{array}{l}\text { COVID ARDS, } \\
\text { matched cohort }\end{array}$ & p value* \\
\hline Number of patients & 91 & 276 & & 91 & \\
\hline Age, years & $69[59,77]$ & $68[60,73]$ & 0.30 & $67[63,73]$ & 0.40 \\
\hline Male sex & $61(67)$ & $207(75)$ & 0.18 & $71(78)$ & 0.14 \\
\hline Respiratory rate, breaths. minute ${ }^{-1}$ & $21[18,25]$ & $22[20,25]$ & 0.16 & $22[20,24]$ & 0.47 \\
\hline PEEP, $\mathrm{cmH}_{2} \mathrm{O}$ & $8[6,10]$ & $10[8,14]$ & $<0.001$ & $10[8,12]$ & $<0.001$ \\
\hline $\mathrm{pH}$ & $7.34[7.26,7.43]$ & $7.32[7.23,7.39]$ & 0.02 & $7.34[7.23,7.39]$ & 0.13 \\
\hline $\mathrm{PaCO}_{2}, \mathrm{mmHg}$ & $44[36,53]$ & $51[44,62]$ & $<0.001$ & $49[44,60]$ & $<0.001$ \\
\hline $\mathrm{BMI}, \mathrm{kg} / \mathrm{m}^{2}$ & $26[22,29]$ & $28[26,32]$ & $<0.001$ & $27[25,31]$ & 0.005 \\
\hline$V_{T}, \mathrm{ml} \cdot \mathrm{kg} \mid \mathrm{BW}$ & $6.4[5.8,7.1]$ & $6.0[5.4,6.5]$ & $<0.001$ & $5.9[5.4,6.3]$ & $<0.001$ \\
\hline $\mathrm{PaO}_{2} / \mathrm{FiO}_{2}$ & $117[89,172]$ & $103[77,138]$ & 0.017 & $108[80,144]$ & 0.12 \\
\hline Predicted FRC, liters & $3.1[2.7,3.6]$ & $3.1[2.6,3.4]$ & 0.07 & $3.10[2.7,3.6]$ & 0.71 \\
\hline Ventilatory Ratio & $1.7[1.3,1.9]$ & $1.9[1.5,2.2]$ & 0.001 & $1.8[1.5,2.1]$ & 0.027 \\
\hline Best $\mathrm{C}_{\mathrm{r} \mathrm{s}^{\prime}} \mathrm{ml} / \mathrm{cmH}_{2} \mathrm{O}$ & $38[29,50]$ & $40[30,48]$ & 0.98 & $40[30,49]$ & 0.82 \\
\hline Best minimum PEEP, $\mathrm{cmH}_{2} \mathrm{O}$ & $6[4,8]$ & $6[2,10]$ & 0.64 & $4[2,8]$ & 0.012 \\
\hline
\end{tabular}

Data are shown as median [interquartile range], or count (percentage)

The last column (*) shows the comparison between non-COVID ARDS and COVID ARDS patients matched for predicted FRC. Best compliance is the highest $\mathrm{C}_{\mathrm{rs}}$ obtained at the tested PEEP levels

Best minimum PEEP is the lowest PEEP level associated with the highest $C_{r s}$

$P E E P$ positive end expiratory pressure, $B M I$ body mass index, $V_{T}$ tidal volume, $I B W$ ideal body weight, $F R C$ functional residual capacity, $C_{r s}$ respiratory system compliance, $A R D S$ acute respiratory distress syndrome

central venous pressure, number of patients on norepinephrine and norepinephrine dose $\left(\mathrm{mcg} \cdot \mathrm{kg}^{-1} \cdot \mathrm{min}^{-1}\right)$ and daily urine output did not differ between COVID and non-COVID ARDS patients. Heart rate and lactate had a statistically significant difference, which we believe is clinically insignificant (median heart rate 92 beats-minute [IQR 78, 105] and 83 [IQR 69, 97] in nonCOVID and COVID ARDS, respectively, $\mathrm{p}=0.001$; median lactate 1.1 [IQR $0.9,1.7] \mathrm{mmol} \cdot \mathrm{l}^{-1}$ and 0.9 [ IQR $0.8,1.2] \mathrm{mmol} \cdot \mathrm{l}^{-1}$ in non-COVID and COVID ARDS, respectively, $\mathrm{p}=0.001$ ).

Figure 2 shows $\mathrm{C}_{\mathrm{rs}}$ at different PEEP levels in nonCOVID ARDS and COVID ARDS, in all enrolled patients and in the subset of patients which were matched for predicted FRC. The association between $\mathrm{C}_{\mathrm{rs}}$ and type of ARDS was not significant in both the complete cohorts $(\mathrm{p}=0.17$, see Additional file 1: Table S1) nor in the matched cohorts $(\mathrm{p}=0.93$, see Additional file 1 : Table S2).

Table 2 shows the results of the propensity score weighted association between $\mathrm{C}_{\mathrm{rs} \text {,avg }}$ and COVID status at different PEEP levels. $\mathrm{C}_{\mathrm{rs}, \mathrm{avg}}$ was not associated with the ARDS type at PEEP 5, 10 and $15 \mathrm{cmH}_{2} \mathrm{O}$, showing a significant association at PEEP 0 , despite a clinically insignificant difference. Estimates for the other variables are displayed in Additional file 1: Table S3.

Figure 3 shows the distribution of $\mathrm{C}_{\mathrm{rs}, \mathrm{avg}}$ at different PEEP levels.
Results of the analyses excluding non-COVID patients with extrapulmonary ARDS are shown in Additional file 1: Tables S4-S7).

Updating the power analysis with collected data, we reached a power of 0.85 in detecting a change in compliance of $4 \mathrm{ml} / \mathrm{cmH}_{2} \mathrm{O}$ between COVID and non-COVID ARDS, with a type I error frequency of 0.05 .

\section{Discussion}

This study shows that $C_{r s}$ is similar between COVID ARDS and non-COVID ARDS when weighted for PEEP level and patients' baseline characteristics.

Previous studies comparing compliance between COVID-ARDS and non-COVID ARDS have shown conflicting results $[3,5,12,20]$, and the debate is still ongoing.

In particular, Haudebourg et al. [3] found similar $\mathrm{C}_{\mathrm{rs}}$ between the COVID and non-COVID ARDS patients, with values close to the ones found in our study $(44 \mathrm{ml} /$ $\mathrm{cmH}_{2} \mathrm{O}$ in COVID e $42 \mathrm{ml} / \mathrm{cmH}_{2} \mathrm{O}$ in non-COVID patients in their study, versus $40 \mathrm{ml} / \mathrm{cmH}_{2} \mathrm{O}$ in COVID e $38 \mathrm{ml} / \mathrm{cmH}_{2} \mathrm{O}$ in non-COVID in our study). However, the authors did not adjust for patient characteristics, the cohorts were small (30 with COVID-ARDS versus 30 with non-COVID ARDS) and patients were not matched. In another work comparing COVID and non-COVID ARDS patients [20], the two cohorts were matched on $\mathrm{PaO}_{2} / \mathrm{FiO}_{2}, \mathrm{FiO}_{2}$, PEEP and tidal volume, but there was 

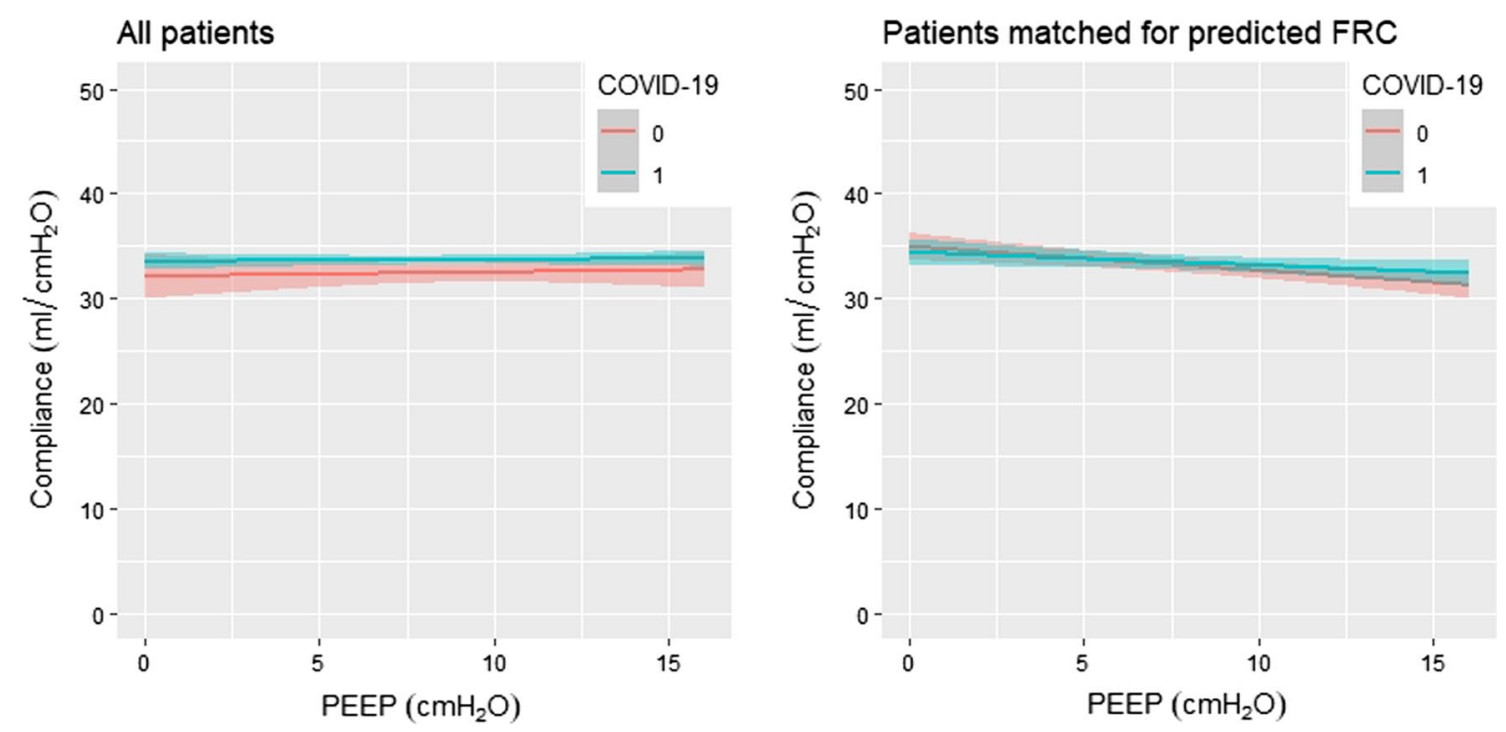

Fig. $2 C_{r s}$ at different PEEP levels. Linear regression showing $C_{r s}$ at different PEEP levels in non-COVID ARDS and COVID ARDS, in all enrolled patients and in the subset of patients which were matched for predicted FRC. $0=$ non-COVID ARDS patients, $1=$ COVID ARDS patients. $C_{r s}$ respiratory system compliance, PEEP positive end expiratory pressure, ARDS acute respiratory distress syndrome, $F R C$ functional residual capacity

Table 2 Results of the propensity score weighted association between $C_{r s, a v g}$ and COVID status at different PEEP levels

\begin{tabular}{llll}
\hline & Non-COVID ARDS & COVID ARDS & p value \\
\hline Number of patients & 91 & 276 & \\
$\mathrm{C}_{\mathrm{rs} \text { avg }}$ at PEEP $0 \mathrm{cmH}_{2} \mathrm{O}$ & $36[26,47]$ & $33[25,42]$ & 0.002 \\
$\mathrm{C}_{\mathrm{rs}, \text { avg }}$ at PEEP $5 \mathrm{cmH}_{2} \mathrm{O}$ & $38[30,48]$ & $37[28,44]$ & 0.10 \\
$\mathrm{C}_{\mathrm{rs}, \mathrm{avg}}$ at PEEP $10 \mathrm{cmH}_{2} \mathrm{O}$ & $35[28,47]$ & $36[29,44]$ & 0.27 \\
$\mathrm{C}_{\mathrm{rs}, \mathrm{avg}}$ at PEEP $15 \mathrm{cmH}_{2} \mathrm{O}$ & $32[22,41]$ & $32[24,40]$ & 0.13 \\
\hline
\end{tabular}

Data are shown as median [interquartile range]

$C_{r s, a v g}$ average respiratory system compliance, PEEP positive end expiratory pressure, ARDS acute respiratory distress syndrome

no adjustment for patient characteristics. Higher $(7 \mathrm{ml} /$ $\mathrm{cmH}_{2} \mathrm{O}$ ) average values of $\mathrm{C}_{\mathrm{rs}}$ were found in COVID-19 patients, but the sample size was small (30 patients) and set and total PEEP were different between COVID and non-COVID patients for both high and low PEEP levels. Other authors [5] found a higher median $\mathrm{C}_{\mathrm{rs}}$ in patients with COVID-19 $\left(41 \mathrm{ml} / \mathrm{cmH}_{2} \mathrm{O}\right)$ than in those with classical ARDS $\left(32 \mathrm{ml} / \mathrm{cmH}_{2} \mathrm{O}\right)$. The analysis was adjusted for sequential organ failure assessment score at ICU admission, sex, age, and $\mathrm{PaO}_{2} / \mathrm{FiO}_{2}$ ratio, but PEEP selection was not protocolized in their patients. Ferrando et al. [12] found a tendency towards the statistical significance (p 0.06) by comparing the $\mathrm{C}_{\mathrm{rs}}$ of non-COVID ARDS patients from different studies and the authors' own data on COVID ARDS patients.

Apart from the intrinsic mechanical properties of the respiratory system, $\mathrm{C}_{\mathrm{rs}}$ is affected by applied PEEP
[7-11]. COVID and non-COVID patients often receive different PEEP levels during mechanical ventilation [4, 20] therefore the comparison of $C_{r s}$ at different PEEP levels could reflect not only the impact of the disease on lung parenchyma but also the effects of the ventilatory treatment. Finding a similar $\mathrm{C}_{\mathrm{rs}}$ with a different applied PEEP in COVID and non-COVID ARDS [4] does not therefore exclude that the elastic properties of the respiratory system would have been different if the same level of positive pressure had been applied. On the other hand, a different $\mathrm{C}_{\mathrm{rs}}$ in COVID and non-COVID ARDS measured at a different PEEP levels cannot exclude similar mechanical properties of the respiratory system if the conditions of measurement had been the same [20].

Moreover, $\mathrm{C}_{\mathrm{rs}}$ depends on the FRC: the physiological variable which links compliance to FRC is called specific compliance (the ratio between $\mathrm{C}_{\mathrm{rs}}$ and FRC) [21-23]. $\mathrm{C}_{\mathrm{rs}}$ is dramatically different in healthy subjects with different FRCs, ranging on average between 5 and $7 \mathrm{ml} / \mathrm{cmH}_{2} \mathrm{O}$ in newborns [20] and $120 \mathrm{ml} / \mathrm{cmH}_{2} \mathrm{O}$ in adults [21]. When $\mathrm{C}_{\mathrm{rs}}$ is normalized by FRC, specific elastance (i.e., the ratio betweenFRC and $C_{r s}$ ) has similar values in healthy newborns, children and adults [24]. In other words, despite similar elastic properties for each milliliter of lung tissue, the same amount of applied pressure gives a different increase in volume (and therefore of $\mathrm{C}_{\mathrm{rs}}$ ) if the FRC is different. Matching for predicted FRC is meaningful when $\mathrm{C}_{\mathrm{rs}}$ is compared in COVID and non-COVID ARDS because FRC depends on height, age, sex and BMI [15, $16,25]$, and some of these characteristics have been 


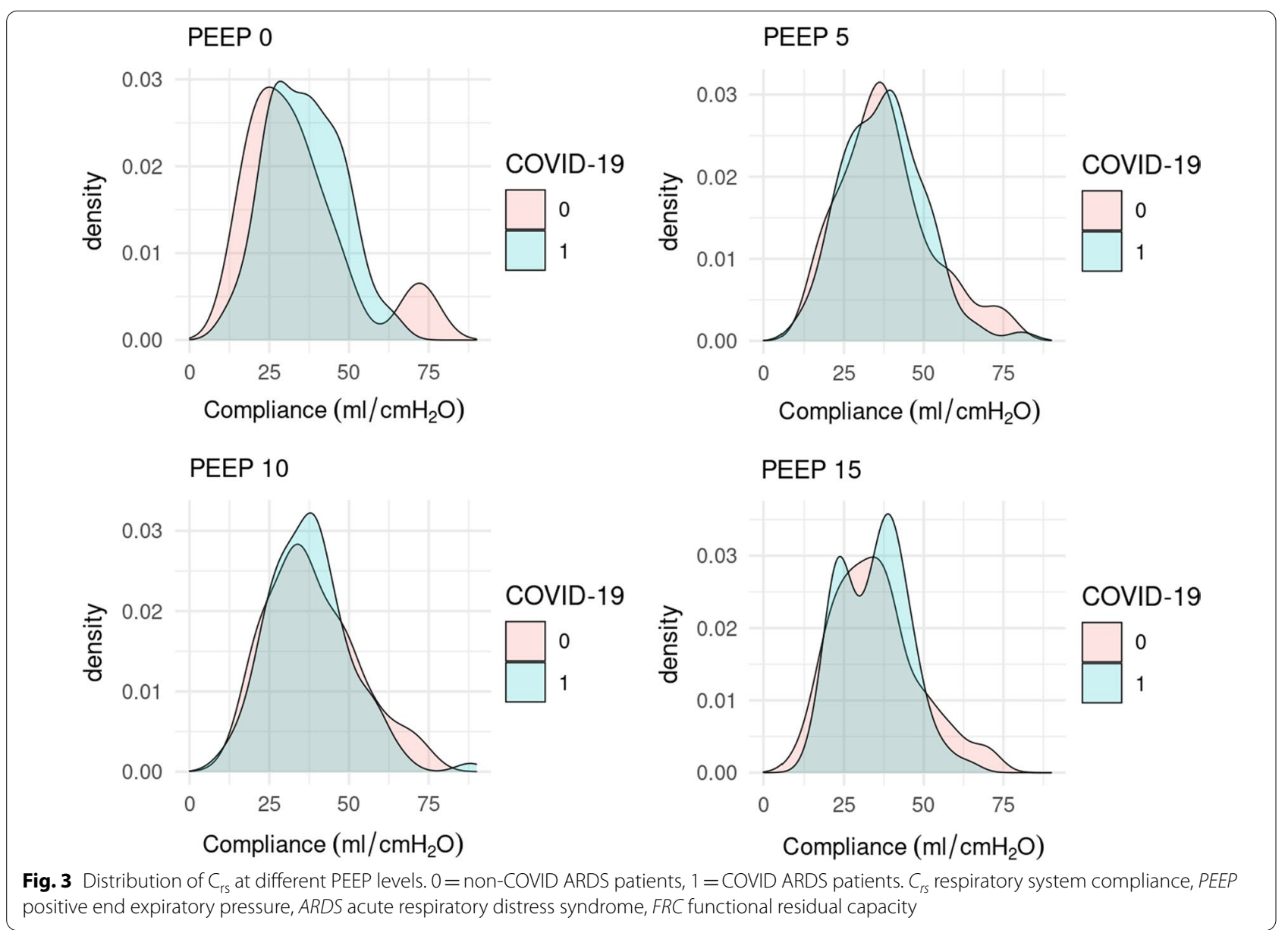

shown to be different in COVID and non-COVID ARDS (mainly sex and BMI) [5].

The effect of a different predicted FRC could explain the findings of Li Bassi et al. [26] who found, in their analysis on COVID-19 ARDS patients, a lower $\mathrm{C}_{\mathrm{rs}}$ in female patients: on average, females have a smaller stature than males, and this predicts lower FRC. Moreover, female sex by itself gives a lower predicted FRC than male sex for the same height and age, whereas BMI, which was higher for female patients in Li Bassi's cohort, has an inverse relationship with predicted FRC. Therefore a lower $\mathrm{C}_{\mathrm{rs}}$ in female patients could be better explained by different anthropometric characteristics than by a different severity of the lung disease.

Based on these pathophysiological premises and clinical data, we designed an analysis which accounted for the effect of both PEEP and FRC.

Our analyses showed that $\mathrm{C}_{\mathrm{rs}}$ is not different between COVID and non-COVID ARDS if assessed at a similar PEEP level when the association was weighted for covariates, when it was carried out in a cohort matched for predicted FRC and when the inverse probability of treatment weighting was used to obtain unbiased estimates of average treatment effects. These results contribute to clarify the debate on the effect of the COVID-19 on alveolar damage, demonstrating that the inflammatory response involving the pulmonary parenchyma in ARDS affects the mechanical properties of the lung regardless of the primary disease. This is consistent with the pattern and definition of ARDS, which is considered as the common final pathway of different pulmonary and extrapulmonary diseases that spread their mediators of inflammation in the lungs $[13,27]$.

The similar pattern of $\mathrm{C}_{\mathrm{rs}}$ in COVID and non-COVID ARDS is supported by a similar best $\mathrm{C}_{\mathrm{rs}}$ obtained during the PEEP trial (median 38 versus $40 \mathrm{ml} / \mathrm{cmH}_{2} \mathrm{O}$ in nonCOVID and COVID ARDS, respectively; see Table 1 for further details), and by a similar lowest PEEP at which the best $\mathrm{C}_{\mathrm{rs}}$ was obtained.

As shown in Fig. 3 it is apparent that, for some patients, a high PEEP level worsens respiratory system compliance, while improving it for some patients. We can therefore speculate that the appearance of two "phenotypes" is in fact the effect of a high PEEP level, and not of COVID 
ARDS itself, but further studies are needed to prove these findings.

Primary analysis was also weighted on dead space, as estimated by Ventilatory Ratio [17], since one of the main differences between COVID and non-COVID ARDS appears to be the dead space ventilation, expression of altered perfusion and vascular endothelial injury $[4,5,28]$. The peculiar increase in dead space ventilation of COVID-19 has been explained as a consequence of pulmonary microvascular thrombosis which locally increases the ventilation/perfusion ratio [5, 28, 29].

The dead space increase in COVID ARDS compared with non-COVID ARDS is confirmed in our analysis, with a higher ventilatory ratio in COVID ARDS compared to non-COVID ARDS in both unmatched and matched cohorts.

This study has two main limitations. First, it is a single center study and therefore requires further confirmation. Nonetheless, since we analyzed the association of $C_{\mathrm{rs}}$ and type of ARDS for a wide range of PEEPs, we believe that our data could be generalized to centers which use a different approach to mechanical ventilation. Second, it is a retrospective study, even if data was prospectively collected. More research is needed on the subject in order to corroborate these findings.

\section{Conclusion}

The compliance of the respiratory system is similar between COVID ARDS and non-COVID ARDS when calculated at the same PEEP level and while taking into account patients' anthropometric characteristics.

\section{Abbreviations}

ARDS: Acute respiratory distress syndrome; COVID-19: Novel coronavirus 2019 disease; $C_{r s}$ : Respiratory system compliance; PEEP: Positive end expiratory pressure; SARS-CoV -2: Severe Acute Respiratory Syndrome-CoronaVirus- 2; RT-PCR: Reverse transcriptase-polymerase chain reaction; ICU: Intensiva care unit; FRC: Functional residual capacity; BMI: Body mass index; IBW: Ideal body weight; $C_{r s, a v g}$ : Average respiratory system compliance.

\section{Supplementary Information}

The online version contains supplementary material available at https://doi. org/10.1186/s12931-022-01930-0.

Additional file 1. Supplementary Material.

\section{Acknowledgements}

Not applicable.

\section{Authors' contributions}

All authors contributed to the data acquisition. FF and GN drafted the manuscript. GN designed and supervised the study. FA and GN conducted the data analysis. All authors contributed substantially to editing, revising and finalizing the manuscript before submission. All authors read and approved the final manuscript.
Funding

No funding was received for this study.

\section{Availability of data and materials}

The datasets used and/or analysed during the current study are available from the corresponding author on reasonable request.

\section{Declarations}

Ethics approval and consent to participate

The protocol was approved by the local ethical committee (Comitato Etico della Provincia di Brescia) with protocol number 4893.

\section{Consent for publication}

Not applicable.

\section{Competing interests}

The authors declare that they have no competing interests.

\section{Author details}

${ }^{1}$ Department of Anesthesia, Intensive Care and Pain Medicine, Fondazione Poliambulanza Hospital, via Bissolati, 57, 25124 Brescia, Italy. ${ }^{2}$ Department of Anesthesiology and Intensive Care Medicine, Catholic University of The Sacred Heart, Rome, Italy. ${ }^{3}$ Department of Anesthesia and Intensive Care, University of Insubria, Varese, Lombardia, Italy.

Received: 12 October 2021 Accepted: 8 January 2022

Published online: 12 January 2022

\section{References}

1. Yang X, Yu Y, Xu J, Shu H, Xia J, Liu H, et al. Clinical course and outcomes of critically ill patients with SARS-CoV-2 pneumonia in Wuhan, China: a single-centered, retrospective, observational study. Lancet Respir Med. 2020;8:475-81.

2. Gattinoni L, Chiumello D, Caironi P, Busana M, Romitti F, Brazzi L, et al. COVID-19 pneumonia: different respiratory treatments for different phenotypes? Intensive Care Med. 2020;46:1099-102.

3. Haudebourg A-F, Perier F, Tuffet S, de Prost N, Razazi K, Mekontso Dessap A, et al. Respiratory mechanics of COVID-19- versus non-COVID-19-associated acute respiratory distress syndrome. Am J Respir Crit Care Med. 2020;202:287-90.

4. Bertelli M, Fusina F, Prezioso C, Cavallo E, Nencini N, Crisci S, et al. COVID19 ARDS is characterized by increased dead space ventilation compared with non-COVID ARDS. Respir Care. 2021;66:1406-15.

5. Grasselli G, Tonetti T, Protti A, Langer T, Girardis M, Bellani G, et al. Pathophysiology of COVID-19-associated acute respiratory distress syndrome: a multicentre prospective observational study. Lancet Respir Med. 2020;8:1201-8.

6. Baedorf Kassis E, Schaefer MS, Maley JH, Hoenig B, Loo Y, Hayes MM, et al. Transpulmonary pressure measurements and lung mechanics in patients with early ARDS and SARS-CoV-2. J Crit Care. 2021;63:106-12.

7. Hess DR. Respiratory mechanics in mechanically ventilated patients. Respir Care. 2014;59:1773-94.

8. Grasso S, Fanelli V, Cafarelli A, Anaclerio R, Amabile M, Ancona G, et al. Effects of high versus low positive end-expiratory pressures in acute respiratory distress syndrome. Am J Respir Crit Care Med. 2005;171:1002-8.

9. Kuckelt W, Scharfenberg J, Mrochen H, Dauberschmidt R, Petrakov G, Kassil W, et al. Effect of PEEP on gas exchange, pulmonary mechanics, and hemodynamics in adult respiratory distress syndrome (ARDS). Intensive Care Med. 1981;7:177-85.

10. Suter PM, Fairley HB, Isenberg MD. Optimum end-expiratory airway pressure in patients with acute pulmonary failure. N Engl J Med. 1975;292:284-9.

11. Mergoni M, Martelli A, Volpi A, Primavera S, Zuccoli P, Rossi A. Impact of positive end-expiratory pressure on chest wall and lung pressurevolume curve in acute respiratory failure. Am J Respir Crit Care Med. 1997;156:846-54. 
12. Ferrando C, Suarez-Sipmann F, Mellado-Artigas R, Hernández M, Gea A, Arruti $\mathrm{E}$, et al. Clinical features, ventilatory management, and outcome of ARDS caused by COVID-19 are similar to other causes of ARDS. Intensive Care Med. 2020;46:2200-11.

13. ARDS Definition Task Force. Acute respiratory distress syndrome: the Berlin definition. JAMA. 2012;307:2526-33.

14. Garnero A, Tuxen D, Corno G, Durand-Gasselin J, Hodgson C, Arnal J-M. Dynamics of end expiratory lung volume after changing positive endexpiratory pressure in acute respiratory distress syndrome patients. Crit Care. 2015;19:340

15. Stocks J, Quanjer PhH. Reference values for residual volume, functional residual capacity and total lung capacity. Eur Respir J. 1995;8:492-506.

16. Jones RL, Nzekwu M-MU. The effects of body mass index on lung volumes. Chest. 2006;130:827-33.

17. Sinha P, Calfee CS, Beitler JR, Soni N, Ho K, Matthay MA, et al. Physiologic analysis and clinical performance of the ventilatory ratio in acute respiratory distress syndrome. Am J Respir Crit Care Med. 2019;199:333-41.

18. Li F, Morgan KL, Zaslavsky AM. Balancing covariates via propensity score weighting. J Am Stat Assoc. 2018;113:390-400.

19. R Core Team. R: A Language and Environment for Statistical Computing. Vienna, Austria: R Foundation for Statistical Computing; 2021. at https:// www.R-project.org/.

20. Grieco DL, Bongiovanni F, Chen L, Menga LS, Cutuli SL, Pintaudi G, et al. Respiratory physiology of COVID-19-induced respiratory failure compared to ARDS of other etiologies. Crit Care. 2020;24:529.

21. Chiumello D, Carlesso E, Cadringher P, Caironi P, Valenza F, Polli F, et al. Lung stress and strain during mechanical ventilation for acute respiratory distress syndrome. Am J Respir Crit Care Med. 2008;178:346-55.

22. Gattinoni L, Pesenti A, Avalli L, Rossi F, Bombino M. Pressure-volume curve of total respiratory system in acute respiratory failure: computed tomographic scan study. Am Rev Respir Dis. 1987;136:730-6.

23. Suter PM, Fairley HB, Isenberg MD. Effect of tidal volume and positive end-expiratory pressure on compliance during mechanical ventilation. Chest. 1978;73:158-62.

24. Phelan PD, Williams HE. Ventilatory studies in healthy infants. Pediatr Res. 1969:3:425-32.

25. Lutfi MF. The physiological basis and clinical significance of lung volume measurements. Multidiscip Respir Med. 2017;12:3.

26. Li Bassi G, Suen JY, Dalton HJ, White N, Shrapnel S, Fanning JP, et al. An appraisal of respiratory system compliance in mechanically ventilated COVID-19 patients. Crit Care. 2021;25:199.

27. Ashbaugh David G, Boyd Bigelow D, Petty Thomas L, Levine BE. Acute respiratory distress in adults. The Lancet. 1967;290:319-23.

28. Fusina F, Albani F, Bertelli M, Cavallo E, Crisci S, Caserta R, et al. Corrected minute ventilation is associated with mortality in the ARDS caused by COVID-19. Respir Care. 2021;66:619-25.

29. Ackermann M, Verleden SE, Kuehnel M, Haverich A, Welte T, Laenger F, et al. Pulmonary vascular endothelialitis, thrombosis, and angiogenesis in COVID-19. N Engl J Med. 2020;383:120-8.

\section{Publisher's Note}

Springer Nature remains neutral with regard to jurisdictional claims in published maps and institutional affiliations.

Ready to submit your research? Choose BMC and benefit from:

- fast, convenient online submission

- thorough peer review by experienced researchers in your field

- rapid publication on acceptance

- support for research data, including large and complex data types

- gold Open Access which fosters wider collaboration and increased citations

- maximum visibility for your research: over $100 \mathrm{M}$ website views per year

At BMC, research is always in progress.

Learn more biomedcentral.com/submissions 